\title{
Antimicrobial Effect of Skin for Allograft and Management in Burn Wound
}

\author{
Kihwan Lim¹, Cheonjae Yoon ${ }^{2}$, Jungsuk Lee ${ }^{1 *}$ \\ ${ }^{1}$ Bestian R \& D Center, Daejeon, Korea \\ ${ }^{2}$ Department of Emergency Medicine, Bestian Seoul Hospital, Seoul, Korea \\ Email: *nostalgie@naver.com
}

How to cite this paper: Lim, K., Yoon, C. and Lee, J. (2017) Antimicrobial Effect of Skin for Allograft and Management in Burn Wound. Open Journal of Organ Transplant Surgery, 7, 1-11.

https://doi.org/10.4236/ojots.2017.71001

Received: December 14, 2016

Accepted: February 11, 2017

Published: February 14, 2017

Copyright $\odot 2017$ by authors and Scientific Research Publishing Inc. This work is licensed under the Creative Commons Attribution International License (CC BY 4.0).

http://creativecommons.org/licenses/by/4.0/

\begin{abstract}
One of the most important functions of skins is to protect our bodies from microbes or pollutant sources. Skins containing physical substances serve as a physical barrier which protects our bodies from pathogens. A healthy skin contains a variety of antibacterial substances such as defensin, cathelicidin and psoriasin. However deep and wide burns cause the skin to lose its original functions, so our skins are exposed to various danger factors. For the burn patients, human alloskin graft serves as a very important temporary biological wound dressing. It protects the wound before autograft procedure, forms revascularization and granulation tissues and protects the wound from an invasion of microbes. This study was conducted with the aim to analyze the antimicrobial effect of cryopreserved allograft (CPA) and glycerol-preserved allograft (GPA) which was a type of allograft widely used for burn patients, and measure the difference in comparison with the fresh skin before processing it. The most common contaminants found in burn patients such as $S$. aureus, $P$. aeruginosa, $C$. albicans and $E$. coli, were used for experiment. The antimicrobial effect against $S$. aureus and $E$. coli was observed in fresh skin and some $\mathrm{CPA}$. In some clinical cases, infection is frequently observed in the wounds treated with allograft, indicating the allograft completely block every kind of microbes. To prevent the infection, it is required to use antibiotics and manage wounds thoroughly.
\end{abstract}

\section{Keywords}

Fresh Skin, CPA (Cryo Preserved Allograft), GPA (Glycerol Preserved Allograft), Infection, Antimicrobial Effect, Allograft

\section{Introduction}

Skin consisting of numerous cells controls the immune response and also serves 
as a primary protective layer [1]. Skin protects our body from invasion of microbes by way of serving as a barrier and discharging a wide range of chemical substances [2] [3]. Skin discharges more than 20 different types of AMP in the event of infection. It is widely known that skin secretes antibiotics such as cathelicidin, defensin, regulated on activation, normal $\mathrm{T}$ cell expressed and secreted (RANTES) reported that psoriasin secreted from keratinocyte showed bactericidal capacity against $E$. coli [4] [5].

However, if skins are burned, dermis and epidermis are destroyed, resulting in inflammation, the malfunction of immune system and infection [6].

In addition, the exudate or tissue necrosis generated in the affected area creates the optimal environment where various microbes can settle [7]. Gram positive bacteria form a colony within 48 hours after getting burned, and then gram negative bacteria form a colony. Gram positive bacteria start appearing within 2 days and gram negative bacteria start appearing within a few days [8]. It was reported that the pathogenic bacteria frequently observed in burn patients such as Pseudomonas aeruginosa, methicillin resistant Staphylococcus aureus (MRSA), Acinetobacter spp. and Candida albicans form a colony in the wound [9].

In the case of wide burn wound, homogeneous human deceased donor skin is used for dressing before conducting allograft procedure. Human deceased donor skin is the most widely used for dressing burn wounds. In general deceased donor skin is preserved in two different ways. First, CPA refers to a method in which the temperature is lowered to $-100^{\circ} \mathrm{C}$ using CRF (Control Rate Freezer) at rate of $-1{ }^{\circ} \mathrm{C}--5^{\circ} \mathrm{C} / \mathrm{min}$; tissues are double-packed in plastic pouch, and then preserved in $-150^{\circ} \mathrm{C}$ deep freezer. Second, GPA refers to a method in which tissues are put in $85 \%$ Glycerol and the refrigerated at $2^{\circ} \mathrm{C}-8^{\circ} \mathrm{C}$. This allograft is said to serve as a mechanical and physiological barrier and reduce the loss of protein and moisture, thereby preventing the bacterial infection [10] [11].

However, even though many studies have reported that skin protect pathogen by secreting the anti-microbial peptide (AMP) such as defensin, there has been very little research reported on the direct anti-microbial effectiveness of allograft. The purpose of this study is therefore to analyze the antimicrobial effect of dressing materials such as donor skin and fresh skin. An experiment was conducted for various factors such as cryoprotectant (glycerol/dimethylsulfoxide (DMSO), keratinocyte cell viability, donor and tissue thickness. 6 kinds of bacterial species causing burn wound infection ( $S$. aureus, E. coli, A. baumani, MRSA, $P$. aeruginosa, $C$. albicans) were cultured, and their antimicrobial effect was tested to analyze their resistance to the contaminants during the skin graft procedure.

\section{Materials \& Method}

\subsection{Skin Sample}

We obtained the Fresh Skin, CPA and GPA from the 6 donors at the Korea Foundation For Human Donation (KFHD). In addition, CPA donor sites were 
prepared from the 8 donors and processed by other protocol \& cryoprotectants. Total number of donors was 14 . By inspecting the quality and passing the quality test at KFHD, using donor skin is suitable for skin graft.

\subsection{Keratinocyte Cell Viability}

Tissue viability was determined by keratinocyte isolation and viability. CPA was carried out in a pre-warm $0.9 \%$ saline solution to thaw and rinsed away three times to remove cryoprotectant. Also GPA was rehydrated by soaking in saline solution at room temperature for $10 \mathrm{~min}$ and rinsed away three times [11].

The tissue viability of CPA, GPA, and fresh skin were analyzed for cell viability. Donor skin samples were cut into small pieces and those pieces were incubated in a $0.1 \%$ Trypsin-EDTA (Gibco, USA) solution for 2 hours at $37^{\circ} \mathrm{C}$. The epidermis harvested with fine forceps and incubated for 30 minutes in $0.025 \%$ Trypsin/EDTA (Gibco, USA) to isolate a single keratinocyte. The cells were harvested by centrifuge and resuspended in KGM (Gibco, USA). Cell viability was measured with $0.4 \%$ Trypan blue (Sigma, USA) by Haemocytometer [12].

\subsection{Microbes Inhibition Assay}

We were tested 6 microbes Staphylococcus aureus (ATCC6538), Escherichia coli (ATCC25922), MRSA (Methicilin resistant staphylococcus aureus, CCARM 3089), Pseudomonas aeruginosa (ATCC9027), Acinetobacterbaumanni (KCCM 40203), Candida albicans (ATCC10231). S. aureus, E. colis, MRSA, P. aeruginosa, A. baumanni were incubated at $37^{\circ} \mathrm{C}$ and $C$. albicans at $25^{\circ} \mathrm{C}$. Single colony were cultured for 8 hours by TSB (Tryptic Soy Broth, BD, USA). By absorbance we were set the volume and spread the TSA agar (Tryptic Soy Agar, BD, USA). After the spread of the appropriate number of microbes in TSA agar plate, donor skin $(0.5 \times 0.5 \mathrm{~cm})$ were located on these agar. These were incubated $S$. aureus, E. coli, MRSA, $P$. aeruginosa, A. baumanni for $24 \mathrm{hrs}$ in $37^{\circ} \mathrm{C}$ and $C$. albicans for $48 \mathrm{hrs}$ in $25^{\circ} \mathrm{C}$. Positive control were used to $10 \%$ penicillin-streptomycin (10,000 unit and $0.85 \% \mathrm{NaCl}$, Hyclone, USA). The zone of inhibition were measured the diameter of clear zone [13].

*. The Numbers of Microbes.

S. aureus. $8.25 \times 10^{5} \mathrm{CFU} / \mathrm{ml}$.

E. coli: $9.0 \times 10^{5} \mathrm{CFU} / \mathrm{ml}$.

A. baumani: $5.56 \times 10^{5} \mathrm{CFU} / \mathrm{ml}$.

MRSA: $2.23 \times 10^{6} \mathrm{CFU} / \mathrm{ml}$.

P. aeruginosa: $4.72 \times 10^{6} \mathrm{CFU} / \mathrm{ml}$.

C. albicans. $4.72 \times 10^{6} \mathrm{CFU} / \mathrm{ml}$.

\subsection{H \& E Stain \& Immunohistochemistry}

Tissues were fixed for $24 \mathrm{hrs}$ by paraformaldehyde and were made paraffin block. Deparaffinized sections were stained Hematoxylin \& Eosin (Cancer Diagnostics, USA). And other deparaffinized sections were immersed in citrate buffer $(0.01 \mathrm{~mol} / \mathrm{L}$ citrate, $\mathrm{pH} 6.0)$ and boiled at microwave for Immunohisto- 
chemistry.

The sections were treated with $3 \% \mathrm{H}_{2} \mathrm{O}_{2}$ for 10 mins and protein blocking buffer (DAKO, USA) for 30 mins to block endogenous peroxidase activity. The sections were treated room temperature $2 \mathrm{hrs}$ with primary antibody [14]. We used the 2 antibodies (Human Beta Defensin-3 [hBD-3, Santacruz, USA), Neutrophil gelatinase-associated lipocalin [NGAL, Santacruz, USA]) and counterstained with hematoxylin [15].

\subsection{Ethics Statement}

The protocol was reviewed and approved by the Institutional Ethics Committee for human studies of the Burn Center at the Bestian Seoul hospital in Seoul, Korea. As this study was based on human biological materials, researchers were prohibited from collecting or recording personal identification information. So we were obtained screening exemption from Bestian hospital IRB Board before conducting this study.

\section{Results}

\subsection{Total Microbial Count}

This test method tested to detect the presence of microorganisms in raw samples. There was a quantitative estimate of the level of microorganisms present in the donor skin sample by total bacteria count method. The results were no bacteria in fresh skin, CPA and GPA samples (Table 1).

\subsection{Antimicrobial Effect \& Cell Viability in the Same Donor}

Fresh skin, CPA, and GPA in the same donor compared the antimicrobial activity. Mostly fresh skin had identified some effects at $S$. aureus (ATCC6538). At

Table 1. Total bacteria and mold count of CPA, GPA and Fresh skin.

\begin{tabular}{cccc}
\hline Donor No. & Fresh skin & CPA & GPA \\
\hline 1 & - & - & - \\
2 & - & - & - \\
3 & - & - & - \\
4 & - & - & - \\
5 & - & - & - \\
6 & - & - & \\
7 & & - & \\
8 & & - & \\
9 & & - & \\
10 & & - & \\
11 & & - & \\
12 & & - & \\
13 & & - & \\
14 & & - & \\
\hline
\end{tabular}

${ }^{*}(-)$ : No colony. 
E. coli (ATCC25922) and MRSA showed antibacterial activity in 2 - 3 samples of 6 samples. But in the CPA only showed antibacterial activity E. coli (ATCC 25922) and $S$. aureus (ATCC6538). In the GPA was found that the antibacterial activity weakened in E. coli (ATCC25922) (Table 2).

The cell viability of fresh skin was an average $72.1 \%$, CPA was $29.25 \%$, GPA was $8.05 \%$.

The correlation between antimicrobial effect and cell viability was no significance among 3 types sample.

\subsection{Antimicrobial Effect in CPA Groups}

We prepared 3 groups of CPA. These were separated cell viability, cryoprotectant and tissue thickness. All group was confirmed that no antibacterial activity ( $P$. aeruginosa, $M R S A, C$. albicans, A. baumannii). However, some CPA samples revealed partially antibacterial activity at $E$. coli (ATCC25922) and $S$. aureus (ATCC6538) (Table 3, Figure 1).

1) Donor

There were showed different antimicrobial activity among donors.

Table 2. The comparison cell viability \& antimicrobial effect of fresh skin, CPA and GPA in the same donor.

\begin{tabular}{|c|c|c|c|c|c|c|c|c|c|c|c|c|c|c|c|c|c|c|}
\hline \multirow[b]{2}{*}{ Donor No. } & \multicolumn{6}{|c|}{ A (Fresh skin) } & \multicolumn{6}{|c|}{$\mathrm{B}(\mathrm{CPA})$} & \multicolumn{6}{|c|}{$\mathrm{C}(\mathrm{GPA})$} \\
\hline & 1 & 2 & 3 & 4 & 5 & 6 & 1 & 2 & 3 & 4 & 5 & 6 & 1 & 2 & 3 & 4 & 5 & 6 \\
\hline Cell viability (\%) & 78.1 & 74.2 & 70.9 & 69.5 & 71.5 & 68.4 & 42.7 & 27.5 & 31.6 & 26.9 & 21.5 & 25.3 & 7.9 & 7.2 & 8.9 & 7.8 & 9.0 & 7.5 \\
\hline E. coli & +++ & & & & + & + & ++ & & & & & & + & & & & & \\
\hline S. aureus & +++ & +++ & + & & + & + & + & & & ++ & + & + & & & & & & \\
\hline \multicolumn{19}{|l|}{$P$. aeruginosa } \\
\hline$M R S A$ & + & & & & + & + & & & & & & & & & & & & \\
\hline \multicolumn{19}{|l|}{ C. albicans } \\
\hline A. baumannii & & & & & & & & & & & & & & & & & & \\
\hline
\end{tabular}

${ }^{*}(+)$ : clear zone < $4 \mathrm{~mm} ;(++)$ : clear zone $4 \mathrm{~mm}-8 \mathrm{~mm}$; (+++): clear zone $>8 \mathrm{~mm}$.

Table 3. The result of anti microbial effect in CPA group ${ }^{\star} \mathrm{D}$.

\begin{tabular}{|c|c|c|c|c|c|c|c|c|c|c|c|c|}
\hline \multirow{3}{*}{ Donor No. } & \multicolumn{6}{|c|}{$\mathrm{D}$} & \multicolumn{4}{|c|}{$\mathrm{E}$} & \multirow{2}{*}{\multicolumn{2}{|c|}{$\begin{array}{l}\mathrm{F} \\
13\end{array}$}} \\
\hline & \multirow{2}{*}{7} & \multirow{2}{*}{8} & \multirow{2}{*}{9} & \multirow{2}{*}{10} & \multirow{2}{*}{11} & \multirow{2}{*}{12} & \multicolumn{2}{|c|}{13} & \multicolumn{2}{|c|}{14} & & \\
\hline & & & & & & & GL & $\mathrm{DM}$ & GL & $\mathrm{DM}$ & Thin & Thick \\
\hline Cell viability (\%) & 44 & 51.2 & 57.8 & 52.6 & 50 & 48.9 & 50.7 & 53.5 & 52.1 & 65.5 & 53.5 & 53.5 \\
\hline E. coli & & & + & & & & +++ & ++ & & & ++ & ++ \\
\hline S. aureus & & + & + & + & & + & + & & & & & \\
\hline \multicolumn{13}{|l|}{ P. aeruginosa } \\
\hline \multicolumn{13}{|l|}{$M R S A$} \\
\hline \multicolumn{13}{|l|}{ C. albicans } \\
\hline A. baumannii & & & & & & & & & & & & \\
\hline
\end{tabular}

${ }^{\star}$ D group: viability; E group: cryoprotectant; F group: skin thickness; ${ }^{\star}(+)$ : clear zone $<4 \mathrm{~mm}$; $(++)$ : clear zone $4 \mathrm{~mm}-8 \mathrm{~mm} ;(+++)$ : clear zone $>8 \mathrm{~mm}$. GL: Glycerol; DM: DMSO. 


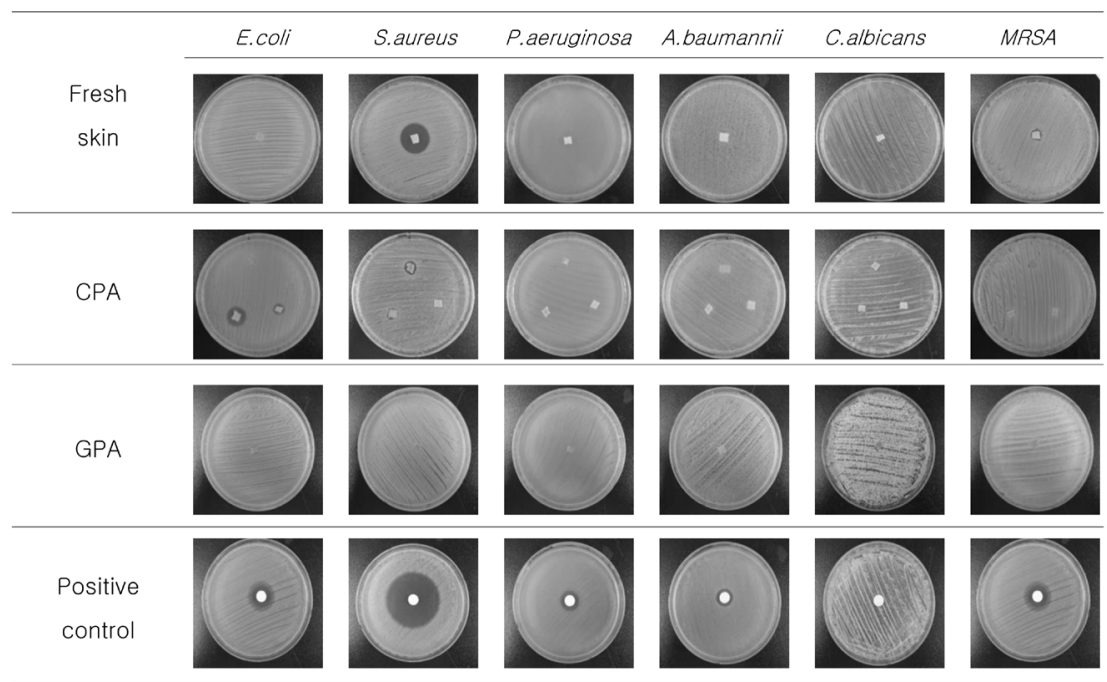

Figure 1. Antimicrobial effect of skin donors. The antibacterial activity were conducted donor skin for graft by 6 microbes Strain. Fresh skin, CPA and GPA was measured the clearzone in E. coli, S. aureus, P. aeruginosa, A. baumani, C. albicans and MRSA.

The frequently detected pathogens in burn wound were $S$. aureus, $P$. aeruginosa, MRSA, C. albicans and A. baumannii. Some CPA of donors had antimicrobial activity but others had not (Table 3). In particulary some CPA of donor had antimicrobial activity at only E. coli (ATCC25922) and S. aureus (ATCC 6538). All CPA of donors had not antimicrobial activity at $P$. aeruginosa, MRSA, C. albicans and A. baumannii.

2) Cell viability of donor tissue

We were measured the relation of cell viability and antimicrobial activity of skin donor.

The average of CPA was $52.6 \%$ cell viability. The best cell viability was measured $65.6 \%$ at No.14 donor. The highest antimicrobial activity was No.13 donor and cell viability of these was measured $50.7 \%-53.5 \%$ (Table 3). There was confirmed that cell viability and antimicrobial activity had no relation.

3) Cryoprotectant

In the manufacture of $\mathrm{CPA}$, it was used cryoprotectant to prevent crystalling and tissue damage. DMSOan glycerol are the most widely and common used for cryoprotectant. We were measured the antibacterial activity of CPA by Glycerol and DMSO. The glycerol group (No.13, 14 donor) was shown the antibacterial activity in E. coli (ATCC25922) and S. aureus (ATCC6538). And the DMSO group (No.13, 14 donor) was found the antibacterial activity only in E. coli (Table 3). There was no difference between CPA by DMSO and glycerol.

4) Thickness of skin

We were measured the differences of antibacterial activity in by tissue thickness. There were not shown the difference of antibacterial activity in same donor tissues. The antibacterial activity showed at E. coli (ATCC25922) in some CPA. There were not shown the difference of antibacterial activity in same donor tissues (Table 3). As a result it confirmed that tissue thickness and antimicrobial activity had no relation. 


\subsection{Comparison of Histopathology}

Some Fresh skin, CPA and GPA were processed for histological analysis. There were performed to verify the tissue architecture and epidermis/dermis junction by $\mathrm{H} \& \mathrm{E}$ stain. All samples showed good conditions. The human epidermis has some immune system to protect harmful factors exposures. Antimicrobial peptides (AMPs) act in epidermis with adaptive immune systems and have broad spectrum antimicrobial activity against microorganisms. To verify the expression AMP in the skin we used to 2 antibodies hBD3 and NGAL by immunohistochemistry. Many CPA and GPA samples were expressed strongly and others were expressed lower or nearly (Figure 2). But there were no relation between AMP expression and antimicrobial effect by tissue thickness, cell viability, cryoprotectant.

\section{Discussion}

Human skin allograft is the most ideal biological dressing and reduces the moisture loss and the pain of patients. It was reported that since human skin allograft covers the wounded area, it reduces a risk of infection, promotes the granulation of tissues and helps healing.

Skin graft is critical to some severe burns patients, thus we intended to analyze the defense activity of important infection in the burn wounds. However the burn patients are exposed in various bacteria even though their wounds are covered with allograft. Ekrami and Lalantar verified throughout their study that 140 of 180 burn patients were exposed to a risk of infection especially by pathogenic bacteria such as $P$. aeruginosa (37.5\%), S. aureus (20.2\%) and A. baumanni (10.4\%) [16]. Mayhall CG also reported the burn patients are exposed to a risk of infection especially by $S$. aureus (23.0\%), P. aeruginosa (19.3\%), E. coli (7.2\%) and $C$. albicans (3.5\%) [17]. So skin grafts wound frequently be lost due to infection in vascular ulcers and burn wounds [18].

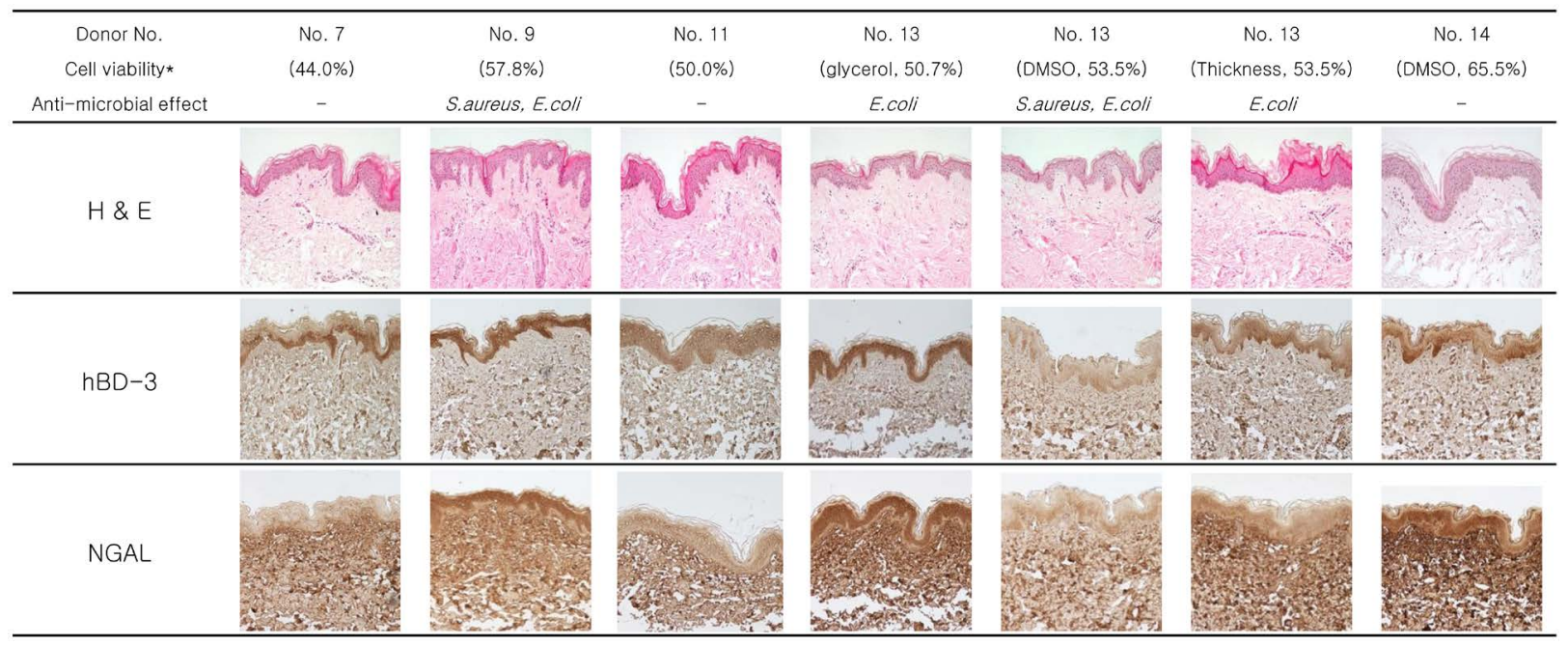

Figure 2. Histopathological analysis of tissue sections. The integrity of tissue architecture at CPA by $\mathrm{H} \& \mathrm{E}$ staining. The expression of HBD-3 (Human Beta Defensin-3) \& NGAL at CPA specimens. ${ }^{*}$ Various factor: cell viability, cryoprotectant, tissue thickness $(\times 200)$. 
Based on the results of the previous studies, we performed an experiment to analyze the antimicrobial effect of CPA and Fresh Skin in conjunction with various factors such as Cryoprotectant (Glycerol/DMSO), keratinocyte cell viability, donor and tissue thickness using 6 types of bacterial species (S. aureus, E. coli, $A$. baumani, MRSA, P. aeruginosa, C. albicans).

The best skin grafts come from the patient's own unburned skin (donor sites) [19]. Thus in patients with burns involving over 50\% total body surface area (TBSA), the patient's donor skin is limited [20]. Currently the method of preservation of the skingraft are CPA and GPA. Our study compared the antimicrobial activity of fresh skin, CPA and GPA. Depending on the methods of processing and storage, we made various allografts. The results showed the there was no difference in antimicrobial effect in conjunction with cell viability and Cryoprotectant (DMSO, Glycerol) used for manufacturing CPA as a freezing solution and the thickness of skin, yet there was a difference according to difference in donors. In addition, it did not show any antimicrobial effect against $P$. aeruginosa, MRSA, A. baumannii and C. albicans whereas it did against E. coli and $S$. aureus.

We analyzed the antimicrobial effect of Fresh Skin, CPA and GPA from the same donor. The results showed that fresh skin in general has an antimicrobial effect against $E$. coli, $S$. aureus, but it does not necessary means CPA and GPA also have an antimicrobial effect. According to one study, 85\% GPA has a strong antimicrobial effect [21]. But the results of this study showed CPA has a mild antimicrobial effect against 6 types of bacterial species. In addition, some donor skins showed low antimicrobial effect against $E$. coli and $S$. aureus.

It is known that skins have AMP acting as endogenous antibiotic, so they kill microbe, thereby protecting skin surface [4].

It was reported that skin secretes various types of antimicrobial protein such as lysozyme, RNase-7 and dermcidin, etc., thereby protecting skins [22].

If our bodies get wounded, antimicrobial peptide called cathelicidin and $\beta$ defensin is secreted to protect skins. Cathelicidin serves to function as an antibacterial agent in the skin and activates the inflammation. $\beta$-defensin, a peptide secreted from keratinocyte, has a antimicrobial effect against gram negative bacteria [15].

Neutrophil gelatinase-associated lipocalin (NGAL) is known to be secreted from the neutrophil in the affected area and has an antimicrobial effect against E. coli [23].

To determine whether antimicrobial peptide exists in GPA and CPA, we performed Immunohistochemistry.

We analyzed the expression of hBD-3 and NGAL. The results showed all demonstrated the similar amount of expression. The expression of NGAL varied depending the donors, yet was not influenced by the antimicrobial effect. This implies that there is a lack of correlation between the expression of AMP and antimicrobial effect.

Despite the use of allograft for treating burns, wounds are infected by various 
bacteria. To prevent the microbial infection, various antibiotics and topical antimicrobial agents have been developed. Stefanides et al. in their study had analyzed 6 types of agents (gentamicin sulfate, mafenide acetate, nitrofurazone, povidone-iodine, silver nitrate, silver sulfadiazine) for their antimicrobial effect [24]. The results showed they had an antimicrobial effect against pathogenic bacteria such as $P$. aeruginosa, $C$. albicans, $S$. aureus and E. coli. Many types of antimicrobial agents such as antibiotics, antiseptic and silver, etc. have been used to prevent the microbial infection unless they are poisonous to cells and within the range of concentration which does not cause damages to tissues [25].

Deceased donor skin used for treating burn patients helps treatment in that it protects wounds from microbes before treating the wounds with autograft. In this study, CPA, GPA and fresh skin used as allograft did not have strong antimicrobial effect. Moreover, there was no correlation the cell viability of deceased donor skin and the amount of AMP.

Skin allografts are used to care for various burn and wound patients. Early surgical removal of burned skin followed by skin grafting reduces the number of days in the hospital and usually improves the healing of the burned area. When the skin allograft is one of the most commonly applied skin substitutes in burn wound management for major burn, the allograft prevents desiccation of the wound bed and also reduces bacterial colonization [26].

\section{Conclusion}

It is considered to be a microbial defense mechanism by mechanical and physiological barrier different from antimicrobial mechanism such as silver or mafenide acetate.

\section{References}

[1] Fulton, C., Mark Anderson, G., Zasloff, M., Bull, R. and Quinn, A.G. (1997) Expression of Natural Peptide Antibiotics in Human Skin. The Lancet, 350, 1750-1751. https://doi.org/10.1016/S0140-6736(05)63574-X

[2] Braff, M.H., Bardan, A., Nizet, V. and Gallo, R.L. (2005) Cutaneous Defense Mechanisms by Antimicrobial Peptides. Journal of Investigative Dermatology, 125, 913. https://doi.org/10.1111/j.0022-202X.2004.23587.x

[3] Montes, L.F., Black, S.H. and McBride, M.E. (1967) Bacterial Invasion of the Stratum Corneum in Erythrasma. Journal of Investigative Dermatology, 49, 474-485. https://doi.org/10.1038/jid.1967.168

[4] Schauber, J. and Gallo, R.L. (2009) Antimicrobial Peptides and the Skin Immune Defense System. Journal of Allergy and Clinical Immunology, 124, 13-18. https://doi.org/10.1016/j.jaci.2009.07.014

[5] Gläser, R., Harder, J., Lange, H., Bartels, J., Christophers, E. and Schröder, J.M. (2005) Antimicrobial Psoriasin (S100A7) Protects Human Skin from Escherichia coli Infection. Nature Immunology, 6, 57-64. https://doi.org/10.1038/ni1142

[6] Milner, S.M., Bhat, S., Buja, M., Gulati, S., Poindexter, B.J. and Bick, R.J. (2004) Expression of Human Beta Defensin 2 in Thermal Injury. Burns, 30, 649-654. https://doi.org/10.1016/j.burns.2004.06.001

[7] Song, W.K., Lee, K.M., Sjin, D.H. and Kim, H.T. (1999) Antimicrobial Susceptibility 
Patterns of Predominant Bacteria Isolated from the Burn Patients. Journal of the Korean Society for Chemotherapy, 17, 47-52.

[8] Church, D., Elsayed, S., Reid, O., Winston, B. and Lindsay, R. (2006) Burn Wound Infections. Clinical Microbiology Reviews, 19, 403-434.

https://doi.org/10.1128/CMR.19.2.403-434.2006

[9] Chim, H., Tan, B.H. and Song, C. (2007) Five-Year Review of Infections in a Burn Intensive Care Unit: High Incidence of Acinetobacter baumannii in a Tropical Climate. Burns, 33, 1008-1014. https://doi.org/10.1016/j.burns.2007.03.003

[10] Hermans, M.H. (2011) Preservation Methods of Allografts and Their (Lack of) Influence on Clinical Results in Partial Thickness Burns. Burns, 37, 873-881. https://doi.org/10.1016/j.burns.2011.01.007

[11] Kua, E.H., Goh, C.Q., Ting, Y., Chua, A. and Song, C. (2012) Comparing the Use of Glycerol Preserved and Cryopreserved Allogenic Skin for the Treatment of Severe Burns: Differences in Clinical Outcomes and in Vitro Tissue Viability. Cell Tissue Bank, 13, 269-279. https://doi.org/10.1007/s10561-011-9254-4

[12] Normand, J. and Karasek, M.A. (1995) A Method for the Isolation and Serial Propagation of Keratinocytes, Endothelial Cells, and Fibroblasts from a Single Punch Biopsy of Human Skin. In Vitro Cellular \& Developmental Biology-Animal, 31, 447-455. https://doi.org/10.1007/BF02634257

[13] Nasir, N.A., Halim, A.S., Singh, K.K., Dorai, A.A. and Haneef, M.N. (2010) Antibacterial Properties of Tualang Honey and Its Effect in Burn Wound Management: A Comparative Study. BMC Complementary and Alternative Medicine, 10, 31. https://doi.org/10.1186/1472-6882-10-31

[14] Hayashi, A., Fumon, T., Miki, Y., Sato, H., Yoshino, T. and Takahashi, K. (2013) The Evaluation of Immunohistochemical Markers and Thymic Cortical Microenvironmental Cells in Distinguishing Thymic Carcinoma from Type $\beta 3$ Thymoma or Lung Squamous Cell Carcinoma. Journal of Clinical and Experimental Hematopathology, 53, 9-19. https://doi.org/10.3960/jslrt.53.9

[15] Harder, J., Bartels, J., Christophers, E. and Schroder, J.M. (2000) Isolation and Characterization of Human Beta-Defensin-3, a Novel Human Inducible Peptide Antibiotic. Journal of Biological Chemistry, 276, 5707-5713. https://doi.org/10.1074/jbc.M008557200

[16] Ekrami, A. and Kalantar, E. (2007) Bacterial Infections in Burn Patients at a Burn Hospital in Iran. Indian Journal of Medical Research, 126, 541-544.

[17] Mayhall, C.G. (2003) The Epidemiology of Burn Wound Infections: Then and Now. Clinical Infectious Diseases, 37, 543-550. https://doi.org/10.1086/376993

[18] Unal, S., Ersoz, G., Demirkan, F., Arslan, E., Tütüncü, N. and Sari, A. (2005) Analysis of Skin-Graft Loss Due to Infection: Infection-Related Graft Loss. Annals of Plastic Surgery, 55, 102-106. https://doi.org/10.1097/01.sap.0000164531.23770.60

[19] http://www.burn-recovery.org/skin-grafts.htm

[20] Wood, F.M., Kolybaba, M.L. and Allen, P. (2006) The Use of Cultured Epithelial Autograft in the Treatment of Major Burn Wounds: Eleven Years of Clinical Experience. Burns, 32, 538-544.

[21] Van Baare, J., Ligtvoet, E.E. and Middelkoop, E. (1998) Microbiological Evaluation of Glycerolized Cadaveric Donor Skin. Transplantation, 65, 966-970. https://doi.org/10.1097/00007890-199804150-00017

[22] Bevins, C.L. (2005) An Important Clue: Fingerprints Point to Psoriasin in Defense against E. coli. Nature Immunology, 6, 12-13. https://doi.org/10.1038/ni0105-12

[23] Goetz, D.H., Holmes, M.A., Borregaard, N., Bluhm, M.E., Raymond, K.N. and 
Strong, R.K. (2002) The Neutrophil Lipocalin NGAL Is a Bacteriostatic Agent That Interferes with Siderophore-Mediated Iron Acquisition. Molecular Cell, 10, 10331043. https://doi.org/10.1016/S1097-2765(02)00708-6

[24] Stefanides, M.M., Copeland, C.E., Kominos, S.D. and Yee, R.B. (1976) In Vitro Penetration of Topical Antiseptics through Eschar of Burn Patients. Annals of Surgery, 183, 358-364. https://doi.org/10.1097/00000658-197604000-00005

[25] Greenhalgh, D.G. (2009) Topical Antimicrobial Agents for Burn Wounds. Clinics in Plastic Surgery, 36, 597-606. https://doi.org/10.1016/j.cps.2009.05.011

[26] Halim, A., Khoo, T. and Yussof, S. (2010) Biologic and Synthetic Skin Substitutes: An Overview. Indian Journal of Plastic Surgery, 43, S23-S28.

https://doi.org/10.4103/0970-0358.70712

Submit or recommend next manuscript to SCIRP and we will provide best service for you:

Accepting pre-submission inquiries through Email, Facebook, LinkedIn, Twitter, etc. A wide selection of journals (inclusive of 9 subjects, more than 200 journals)

Providing 24-hour high-quality service

User-friendly online submission system

Fair and swift peer-review system

Efficient typesetting and proofreading procedure

Display of the result of downloads and visits, as well as the number of cited articles Maximum dissemination of your research work

Submit your manuscript at: http://papersubmission.scirp.org/

Or contact ojots@scirp.org 